OPEN ACCESS

Edited by:

Mika Tarvainen,

University of Eastern Finland, Finland

Reviewed by:

Vitor E. Valenti,

Federal University of São Paulo, Brazil

Eron Grant Manusov,

The University of Texas Rio Grande

Valley, United States

*Correspondence:

Robert L. Drury

rl.drury@gmail.com

Specialty section:

This article was submitted to Family Medicine and Primary Care,

a section of the journal

Frontiers in Medicine

Received: 31 August 2017

Accepted: 16 January 2019

Published: 06 February 2019

Citation:

Drury RL and Simonetti SA (2019)

Heart Rate Variability in Dental

Science. Front. Med. 6:13.

doi: 10.3389/fmed.2019.00013

\section{Heart Rate Variability in Dental Science}

\author{
Robert L. Drury ${ }^{1,2 *}$ and Scott A. Simonetti ${ }^{3}$ \\ ${ }^{1}$ ReThink Health, Bainbridge Island, WA, United States, ${ }^{2}$ Institute for Discovery, University of Wisconsin, Madison, WI, United \\ States, ${ }^{3}$ Advanced Facialdontics LLC, New York, NY, United States
}

Dentistry has made progress as a profession by integration with both medicine and other human sciences, especially when it uses empirical metrics to study process and outcome variables. Notably, progress in our understanding of genomic, biomic, and other molecular biological phenomena has been valuable. As has been identified by Drury (1, 2), it is proposed in this commentary that the inclusion of heart rate variability (HRV) as a biomarker of health may further this integrative progress. HRV is derived by various linear and non-linear statistical analyses of the R-R, beat-to-beat ECG interval in microseconds. Over twenty three thousand reports are identified in a recent PubMed search of the term heart rate variability, most of which demonstrate HRV's sensitivity to a wide diversity of physical and psychosocial pathologies. The small literature of dental use of HRV in both assessment and treatment will be selectively reviewed and relevant exemplars for other important health applications of HRV will be discussed. This will lead to a proposed agenda for researching HRV's value to professional dentistry as a human health and wellness profession.

\section{Keywords: heart rate variability, research priorities, dental assessment, dental procedures, dental science}

Before HRV was specifically identified, it was well-known that dentistry involved negative affective states such as fear, stress, and pain. Indeed, "painless dentistry" was a key marketing feature of some practitioners, and "gentle dentistry" is still a frequent practice name. Although originally using rather unsophisticated unidimensional approaches, our increasing knowledge of biomedicine, neuroscience, and psychosocial issues has led to recent findings summarized by Flaten and al Absi (3) on the cardiovascular and neuroendocrine elements of response to stressful dental treatments. Similarly, the effects of dental surgery on cardiovascular and sympathetic responses have been observed (4), as well as deep pressure input on the parasympathetic system in wisdom tooth extraction (5).

As awareness and understanding of HRV have matured, as in this Research Topic, it has been used in a variety of ways to aid in both assessment and treatment of dental issues and conditions (6). For example the suppression of HRV in malocclusion has been demonstrated by Ekuni et al. (7) and the non-linear characteristics of HRV during endodontic treatment have been identified (8). HRV has been used to monitor orthostatic dysfunction during postural change in the dental chair (9). Several studies have used HRV analysis in the treatment of burning mouth syndrome $(10,11)$.

In an especially salient study, the OPPERA (Orofacial Pain: Prospective Evaluation and Risk Assessment) case-controlled study followed 1633 Tempero Mandibular Dysfunction-free controls and 185 TMD cases for several years at multiple dental universities. The primary finding that emerged from the initial studies of potential risk factors was relative to controls, TMD cases displayed a dysfunction in autonomic activity characterized by reduced HRV at rest and in response to both physical and psychological stressors (12). This was reflected by a decrease in all HRV 
measures in both time and frequency domain during each of the test epochs. There is emerging evidence that somatosensory disorders such as TMD and Fibromyalgia are associated with a reduction in HRV and an overall dysfunction in autonomic activity (13). The association between TMD and headaches (14) coupled with the evidence that headache patients also have increased sympathetic nervous system activity and decreased parasympathetic activity compared to non-headache controls (15), clarifies the emerging need to measure and monitor HRV in dentistry. TMD, being one of the most common chief complaints a dentist may encounter, has always been thought of as a "stress" syndrome, but HRV now provides a quantitative method to assess, diagnose, and measure treatment effectiveness. Addressing, and possibly improving a biomarker such as HRV via a common dental disorder such a TMD, will allow for the potential improved understanding of comorbid symptoms such as migraine and tension headaches, myofascial pain, and fibromyalgia. With the decreasing cost and increasing accuracy of modern biosensors, it is realistic to expect HRV monitoring to become ubiquitous within the dental profession to enhance and measure treatment process and efficacy.

Beyond the use of HRV in assessment of dental processes and interventions, it has been used in applications which include treatment for physical disorders and psychosocial conditions. HRV Biofeedback (HRVB) has been studied in a number of clinical applications in cardiac rehabilitation and impaired sleep quality (16). HRVB has also shown value in modulating emotional response $(17,18)$ and treating disorders such as depression (19), stress (20), pain (21), post-traumatic stress

\section{REFERENCES}

1. Drury RL. Wearable biosensor systems and resilience: a perfect storm in health care? Front Psychol. (2014) 5:853. doi: 10.3389/fpsyg.2014.00853

2. Drury, RL. Unraveling health as a complex adaptive system: data mining, cloud computing, machine learning and biosensors as synergistic technologies. Int J Genomics Data Min. (2017).

3. Flaten MA, al'Absi, M. editors. Cardiovascular and Neuroendocrine Responses During Acute Stress Induced by Different Types of Dental Treatment. In: Neuroscience of Pain, Stress, and Emotion: Psychological and Clinical Aspects. London: Academic Press (2016).

4. Nakamura Y, Matsumura K, Miura K, Kurokawa H, Abe I, Takata Y. Cardiovascular and sympathetic responses to dental surgery with local anesthesia. Hypertens Res. (2001) 24:209-14. doi: 10.1291/hypres.24.209

5. Chen HY, Yang H, Meng LF, Chan PS, Yang CY, Chen HM. Effect of deep pressure input on parasympathetic system in patients with wisdom tooth surgery $J$ Formos Med Assoc. (2016) 115:853-9. doi: 10.1016/j.jfma.2016.07.008

6. Wolf DL, Desjardins PJ, Black PM, Francom SR, Mohanlal RW, Fleishaker JC. Anticipatory anxiety in moderately to highly-anxious oral surgery patients as a screening model for anxiolytics: evaluation of alprazolam. J Clin Psychopharmacol. (2003) 23:51-7. doi: 10.1097/00004714-200302000-00009

7. Ekuni D, Takeuchi N, Furuta M, Tomofuji T, Morita M. Relationship between malocclusion and heart rate variability indices in young adults: a pilotstudy. Methods Inform Med. (2011) 50:358-63. doi: 10.3414/ME10-01-0045

8. Santana MD, Pita Neto IC, Martiniano EC, Monteiro LR, Ramos JL, Garner DM, et al. Non-linear indices of heart rate variability during endodontic treatment. Braz Oral Res. (2016) doi: 10.1590/1807-3107BOR-2016.vol30.0029. [Epubh ahead of print]. disorder (22), and substance use disorder (23). Conversely, exercise therapy has been studied empirically and found to improve HRV (24) and some pharmacological agents have been shown to improve $\operatorname{HRV}(25,26)$, as has hypnosis $(27)$, message (28), and yoga (29). These results are encouraging but they have not been applied to dental treatment issues as of yet.

This general commentary has highlighted the rapidly emerging body of findings showing HRV to be a significant biomarker of various human health conditions, diseases and important functional states. Applications of such findings to dental practice have not been made in the dental literature and this should be a high priority. Not only is HRV of great potential use in assessing and evaluating various dental conditions and procedures, but it has also been helpful in treating a wide variety of non-dental conditions, and may well-generalize in dental treatment. In particular, rapid advances in wearable biosensors, networked algorithmic streamed data analysis and feedback, machine learning, artificial intelligence, and epigenetics will strongly contribute to the overall development of the fields of human health and well-being. This period of rapid technological development $(2,30)$ has been identified in the current Research Topic and presents a major opportunity for dental science.

\section{AUTHOR CONTRIBUTIONS}

$\mathrm{RD}$ conducted the overview of heart rate variability literature relevant to dental practice. He identified contributions and the need for additional research in this area. SS reviewed the manuscript.

9. Momota Y, Tomioka S, Furukita M, Fujisawa K, Takano H, Azuma M. Orthostatic dysregulation during postural change on the dental chair and intraoperativemonitoring by heart rate variability analysis. Case Rep Dent. (2014) 2014:656045. doi: 10.1155/2014/656045

10. Momota Y, Takano H, Kani K, Matsumoto F, Motegi K, Aota K, et al. Frequency analysis of heart rate variability: a useful assessment tool of linearly polarized near-infrared irradiation to stellate ganglion area for burning mouth syndrome Pain Med. (2013) 14:351-7. doi: 10.1111/pme.12008

11. Hanada K. Glossodynia and the function of the autonomic nervous systemfrequency spectrum analysis of RR intervals recorded electrocardiographically Kokubyo Gakkai Zasshi. (2003) 70:124-30. doi: 10.5357/koubyou. 70.124

12. Maixner W, Greenspan JD, Dubner R, Bair E, Mulkey F, Miller V, et al. Potential autonomic risk factors for chronic TMD: descriptive data and empirically identified domains from the OPPERA case-control study. J Pain (2011) 12(11 Suppl.):T75-91. doi: 10.1016/j.jpain.2011.09.002

13. Cohen H, Neumann L, Shore M, Amir M, Cassuto Y, Buskila D. Autonomic dysfunction in patients with fibromyalgia: Application of power spectrum analysis of heart rate variability. Semin Arthritis Rheum. (2000) 29:217-27. doi: 10.1016/S0049-0172(00)80010-4

14. Gonçalves DA, Bigal ME, Jales LC, Camparis CM, Speciali JG. Headache and symptoms of temporomandibular disorder: an epidemiological study. Headache (2010) 50:231-41. doi: 10.1111/j.1526-4610.2009.01511.x

15. Gass JJ, Glaros AG. Autonomic dysregulation in headache patients. Appl Psychophysiol Biofeedback (2013) 38:257-63. doi: 10.1007/s10484-013-9231-8

16. Climov D, Lysy C, Berteau S, Dutrannois J, Dereppe H, Brohet C, et al. Biofeedback on heart rate variability in cardiac rehabilitation: practical feasibility and psycho-physiological effects. Acta Cardiol. (2014) 69:299-307. doi: 10.1080/AC.69.3.3027833 
17. Peira N, Fredrikson M, Pourtois G. Controlling the emotional heart: heart rate biofeedback improves cardiac control during emotional reactions. Int $J$ Psychophysiol. (2014) 91:225-31. doi: 10.1016/j.ijpsycho.2013.12.008

18. Peira N, Pourtois G, Fredrikson M. Learned cardiac control with heart rate biofeedback transfers to emotional reactions. PLoS ONE (2013) 23:e70004. doi: 10.1371/journal.pone.0070004

19. Chien HC, Chung YC, Yeh ML, Lee JF. Breathing exercise combined with cognitive behavioural intervention improves sleep quality and heart rate variability in major depression. J Clin Nurs. (2015) 24:21-22. doi: 10.1111 /jocn. 12972

20. van der Zwan JE, de Vente W, Huizink AC, Bögels SM, de Bruin EI. Physical activity, mindfulness meditation, or heart rate variability biofeedback for stress reduction: a randomized controlled trial. Appl Psychophysiol Biofeedback (2015) 40:257-68. doi: 10.1007/s10484-015-9293-x

21. Berry ME, Chapple IT, Ginsberg JP, Gleichauf KJ, Meyer JA, Nagpal ML. Non-pharmacological intervention for chronic pain in veterans: a pilot study of heart rate variability biofeedback. Glob Adv Health Med. (2014) 3:28-33. doi: 10.7453/gahmj.2013.075

22. Tan G, Dao TK, Farmer L, Sutherland RJ, Gevirtz R. Heart rate variability (HRV) and posttraumatic stress disorder (PTSD): a pilot study. Appl Psychophysiol Biofeedback (2011) 36:27-35. doi: 10.1007/s10484-010-9141-y

23. Eddie D, Kim C, Lehrer P, Deneke E, Bates ME. A pilot study of brief heart rate variability biofeedback to reduce craving in young adult men receiving inpatient treatment for substance use disorders. Appl Psychophysiol Biofeedback (2014) 39:181-92. doi: 10.1007/s10484-0149251-z

24. Routledge FS, Campbell TS, McFetridge-Durdle JA, Bacon SL. Improvements in heart rate variability with exercise therapy. Can J Cardiol. (2010) 26:303-12. doi: 10.1016/S0828-282X(10)70395-0

25. Ozdemir M, Arslan U, Türkoglu S, Balcioglu S, Cengel A. Losartan improves heart rate variability and heart rate turbulence in heartfailure due to ischemic cardiomyopathy. J Card Fail. (2007) 13:812-7. doi: 10.1016/j.cardfail.2007.08.002

26. Aronson D, Burger AJ. Effect of beta-blockade on heart rate variability in decompensated heart failure. Ann Noninvasive Electrocardiol. (2001) 6:98106. doi: 10.1111/j.1542-474X.2001.tb00093.x

27. Smith SL, Lux R, Haley S, Slater H, Beachy J, Moyer-Mileur LJ. The effect of massage on heart rate variability in preterm infants. J Perinatol. (2013) 33:59-64. doi: 10.1038/jp.2012.47

28. Ramírez-Carrasco A, Butrón-Téllez Girón C, Sanchez-Armass O, PierdantPérez M. Effectiveness of hypnosis in combination with conventional techniques of behavior management in anxiety/pain reduction during dental anesthetic infiltration. Pain Res Manag. (2017) 2017:1434015. doi: 10.1155/2017/1434015

29. Cheema BS, Houridis A, Busch L, Raschke-Cheema V, Melville GW, Marshall PW, et al. Effect of an office worksite-based yoga program on heart rate variability: outcomes of a randomized controlled trial. BMC Complement Altern Med. (2013) 13:82. doi: 10.1186/1472-6882-13-82

30. Monkaresi H, Calvo RA, Yan H. A machine learning approach to improve contactless heart rate monitoring using a webcam. IEEE J Biomed Health Inform. (2014) 18:1153-60. doi: 10.1109/JBHI.2013.2291900

Conflict of Interest Statement: The authors declare that the research was conducted in the absence of any commercial or financial relationships that could be construed as a potential conflict of interest.

Copyright (C) 2019 Drury and Simonetti. This is an open-access article distributed under the terms of the Creative Commons Attribution License (CC BY). The use, distribution or reproduction in other forums is permitted, provided the original author(s) and the copyright owner(s) are credited and that the original publication in this journal is cited, in accordance with accepted academic practice. No use, distribution or reproduction is permitted which does not comply with these terms. 